\title{
Enduring Elevations of Hippocampal Amyloid Precursor Protein and Iron Are Features of $\beta$-Amyloid Toxicity and Are Mediated by Tau
}

\author{
Xuling Li ${ }^{1,2} \cdot$ Peng Lei ${ }^{2}$ (D) Q Qingzhang Tuo ${ }^{2,3} \cdot$ Scott Ayton $^{2} \cdot$ Qiao-Xin $\mathrm{Li}^{2} \cdot$ Steve Moon $^{2}$ • \\ Irene Volitakis $^{2} \cdot$ Rong Liu $^{3}$ • Colin L. Masters ${ }^{2} \cdot$ David I. Finkelstein ${ }^{2} \cdot$ Ashley I. Bush $^{2}$
}

Published online: 11 August 2015

(C) The American Society for Experimental NeuroTherapeutics, Inc. 2015 reduction, tau phosphorylation, and iron accumulation, were observed. While the results from our study support the amyloid cascade hypothesis, they also suggest that downstream effectors of $A \beta$, which propagate toxicity after $A \beta$ has been cleared, may be tractable therapeutic targets.

Keywords Alzheimer's disease · Iron · Tau · $\beta$-Amyloid · Aging $\cdot$ Neuroprotection

\section{Introduction}

The defining pathologies of Alzheimer's disease (AD) - senile plaques and neurofibrillary tangles - are thought to be linked in a molecular pathway involving $\beta$-amyloid $(\mathrm{A} \beta)$ and tau protein, the key constituents of the respective pathologies. Proponents of the amyloid cascade hypothesis posit that $A \beta$ recruits tau protein as a downstream effector of toxicity. $A \beta$ induced cytotoxicity was shown to be tau-dependent in primary neuronal culture: the neurons are protected when tau is lowered by either genetic ablation [knockout (KO)], or by leaving them undifferentiated (where they express lower tau levels than differentiated neurons) $[1,2]$. Ex vivo studies of tau KO neurons revealed that the $A \beta$-induced axonal transport deficits and impairment of hippocampal long-term potentiation were mediated by tau [3, 4]. Reduction of endogenous tau was also shown to ameliorate cognitive behavioral deficits and the death rate of amyloid precursor protein (APP) transgenic mice [5-7]. Thus, lowering tau is a promising therapeutic concept for AD.

However, chronic loss of tau itself causes impairment to long-term potentiation and long-term depression [8-10], and tau KO mice exhibit cognitive deficits as early as 4-6 months of age $[8,10]$. Aged tau KO mice $(\geq 12$ months old) have motor and cognitive impairment that accompanies brain 
atrophy [11-13], caused by brain iron [11, 14]. It is thus unclear how the reduction of tau can both precipitate cognitive decline and protect against $A \beta$-induced toxicity. To further complicate this picture, young (4-7 months old) human APP (hAPP) transgenic mice crossbred with $\mathrm{KO}$ mice (hAPP/tau ${ }^{-/-}$ mice) exhibit better cognitive function than APP transgenic mice that express tau normally [5-7]; however, aged (12 months old) hAPP/tau ${ }^{-/-}$mice showed enhanced neurodegeneration than the single APP transgenic mice [15].

We considered whether these results might be explained by altered interactions between APP and tau, rather than tau and $A \beta$. It has not yet been shown that loss of tau protects against $A \beta$ induced (as opposed to APP-induced) toxicity in an animal model, and it is not known how $\mathrm{A} \beta$ recruits tau to cause toxicity. This distinction between APP and A $\beta$ is important in understanding the molecular pathway of $\mathrm{AD}$. It has previously been shown that tau binds to APP [16], and we showed that tau is necessary for the trafficking of APP to the neuronal surface [11]. In this role, tau facilitates the export of iron as APP stabilizes surface ferroportin, which is the obligate iron export protein [11]. As a result, tau KO mice develop irondependent neurodegeneration after the age of 6 months, which can be rescued by iron chelation [11, 14]. This is important because cortical iron elevation has also been implicated in $\mathrm{AD}$ pathogenesis [17].

To test whether toxicity of $A \beta$ itself is influenced by the presence of tau in vivo, we utilized an $\mathrm{A} \beta$ injection model [18]. This model precludes potential interactions between tau and APP, which could have confounded previous findings in tau $\mathrm{KO}$ mice attributed to $A \beta$. We injected preprepared $A \beta$ oligomers into the brains of tau KO mice (C57/B16 background) at 3 months of age or 12 months of age, and studied the behavioral and biochemical consequences. We found that tau $\mathrm{KO}$ mice at both ages are protected against $\mathrm{A} \beta$ oligomer toxicity.

\section{Methods}

\section{Mice and Mice Tissue Preparation}

All mice were housed in a conventional animal facility according to standard animal care protocols and fed standard laboratory chow (Code 102108, Barastoc; Ridley AgriProducts, Melbourne, Australia) and tap water ad libitum. All animal procedures were approved by the Florey Institute's animal ethics committee (13-023) and were performed in accordance with the National Health and Medical Research Council guidelines. Tau KO mice were backcrossed for 10 generations onto a B16 background, and mutants were backcrossed to the parental inbred strain every 3 generations [19]. To obtain the mouse brain, mice were euthanized with an overdose of sodium pentobarbitone (Lethabarb, $100 \mathrm{mg} / \mathrm{kg}$,
Virbac (Australia) Pty. Ltd; Milperra, NSW, Australia) and perfused with ice-cold saline. The right brain hemisphere was microdissected and stored at $-80{ }^{\circ} \mathrm{C}$ until required. The left brain hemisphere was fixed either in $4 \%$ paraformaldehyde for $24 \mathrm{~h}$, and then transferred to $30 \%$ sucrose plus phosphate-buffered saline (PBS; pH 7.4), or in $10 \%$ neutralbuffered formalin for immunohistochemistry.

\section{$\beta$-Amyloid Oligomer Preparation}

$A \beta$ oligomer preparation was performed as previously described [18]. Briefly, $A \beta_{1-42}$ oligomers were prepared by diluting $5 \mathrm{mM}$ human $\mathrm{A} \beta_{1-42}$ (with $95 \%$ purity by reverse phase high-performance liquid chromatography; Chinapeptides, Shanghai, China) in dimethyl sulfoxide to $100 \mu \mathrm{M}$ in ice-cold cell culture medium (phenol red-free Ham's F-12), immediately vortexing for $30 \mathrm{~s}$, and incubating at $4{ }^{\circ} \mathrm{C}$ for $24 \mathrm{~h}$. The solution was then centrifuged at $14,000 \times$ $g$ for $10 \mathrm{~min}$ at $4{ }^{\circ} \mathrm{C}$ to remove insoluble aggregates, and the supernatants containing soluble $\mathrm{A} \beta_{1-42}$ were transferred to clean tubes for injection. Each preparation of $A \beta$ oligomer was freshly made prior to injection.

\section{Stereotactic Injection}

Mice (70\% female) were injected intraperitoneally with anesthetic and analgesic before the stereotactic injection. Mice were anesthetized, and sedation was maintained with an anesthesia gas mask administering isofluorane and oxygen within the stereotaxic instrument (MD3000; Basi, West Lafayette, IN, USA). PBS or A $\beta_{1-42}$ oligomer $(2 \mu 1,0.44 \mathrm{mg} / \mathrm{ml}$ peptide, $0.5 \mu \mathrm{l} / \mathrm{min}$ ) was injected (25-gauge injection needle connected by polyethylene tubing to 5 - $\mu$ l Hamilton microsyringes) into the hippocampal dorsal CA1 area bilaterally. The coordinates from bregma used for CA1 region were as follows: anteroposterior, $-2.3 \mathrm{~mm}$; mediolateral, $-2.0 \mathrm{~mm}$; dorsoventral, $-2.0 \mathrm{~mm}$. The injection needle was inserted $0.5 \mathrm{~mm}$ beyond the tip of the cannula. Mice were allowed to recover on a heating pad and returned to the animal facility.

\section{Y-Maze Test}

The Y-maze test was performed as previously described [11]. Briefly, all mice were subjected to a 2-trial Y-maze test separated by a 1-h intertrial interval to assess spatial recognition memory, with all testing performed during the light phase of the circadian cycle. Behaviors were recorded on video during a 5-min trial and Ethovision video-tracking system (Noldus, Wageningen, the Netherlands) was used for blinded analysis. Data are expressed as the percentage of frequency for novel arm entries made during the 5-min trial. 


\section{Novel Objective Recognition Test}

Twenty-four $\mathrm{h}$ prior to the test, the mice were habituated to the arenas $(50 \mathrm{~cm} \times 50 \mathrm{~cm}$ plastic container) for $5 \mathrm{~min}$ without objects. Arenas were cleaned with ethanol between each habituation period. The day after the mice re-entered the arenas from the same starting point of the arena (facing the bottom left corner) and were granted $10 \mathrm{~min}$ to familiarize themselves with the objects $(50 \mathrm{ml}$ tubes $\times 2$ spaced $10 \mathrm{~cm}$ apart $)$. After each familiarization period the arena and objects were cleaned with ethanol. Exactly $1 \mathrm{~h}$ after the familiarization period, 1 of the 50-ml tubes was replaced with a T75 tissue culture flask as the "novel" object, and the mice were granted $10 \mathrm{~min}$ to explore both objects. This recall period was recorded on camera for subsequent blinded analysis on the TopScan Cleversys suite. Four mice were tested in each run and 3 batches of 4 mice were tested every hour. TopScan Cleversys was used to measure the frequency and duration the mice sniffed the objects within the 10-min recall period.

\section{Nissl Staining}

Paraformaldehyde fixed frozen sections were air-dried for $30 \mathrm{~min}$ prior to staining. The slides were then placed into a slide rack and immersed in $1 \%$ Neutral Red for $2 \mathrm{~min}$. The slides were then rinsed, placed into a series of ethanol concentrations, ranging from $50 \%$ to $100 \%$, and immersed into xylene twice for 5 min each. The slides were then coverslipped using DPX mounting medium (BDH, Trajan Scientific Australia Pty Ltd, Ringwood, VIC, Australia) and air-dried.

\section{Immunohistochemistry}

Frozen, paraformaldehyde-fixed sections were air-dried, and a wax pen was used to circle around each group of sections. The slides were blocked for $30 \mathrm{~min}$ at room temperature (RT; blocking solution: $6 \%$ normal goat serum, $3 \%$ Triton X $10 \%$, in PBS), then incubated with primary antibody [1E8 for $\mathrm{A} \beta$ (in house); Anti Neu-N, clone A-60 (Millipore, Darmstadt, Germany), 1:200 in 1\% normal goat serum, $3 \%$ Triton X $10 \%$, and PBS] for $48 \mathrm{~h}$ at $4{ }^{\circ} \mathrm{C}$ in a humidified staining chamber. The slides were then washed and incubated with secondary antibody (biotinylated sheep antimouse immunoglobulins, 1:400; Chemicon, Temecula, CA, USA) for $2 \mathrm{~h}$ at RT. After incubation with secondary antibody, the slides were incubated with avidin peroxidase solution $(0.08 \%$ avidin peroxidase, $0.75 \%$ Triton X $10 \%$, in $0.1 \mathrm{M}$ phosphate buffer) for $1 \mathrm{~h}$ at RT and 3,3'-diaminobenzidine solution (1\% 3,3'-diaminobenzidine, $2.5 \%$ of $1 \%$ cobalt chloride, and $2 \%$ ammonium nickel sulfate, in $0.1 \mathrm{M}$ phosphate buffer) for $20 \mathrm{~min}$ rocking at RT. Three precent $\mathrm{H}_{2} \mathrm{O}_{2}$ were added onto the slides for chromogen development.

\section{Image Quantification}

Hippocampal sections from mice were sectioned using a Leica Cryostat set at $50 \mu$ thickness (Leica Microsystems, Milton Keynes, UK). The analysis was performed by 2 independent investigators (blinded to mouse identity) by using the color threshold function of Image J $1.49 \mathrm{~m}$ software (National Institutes of Health, Bethesda, MD, USA). Six sections corresponding to the brain region of interest (Bregma $-2.8 \mathrm{~mm}$ to $-3.4 \mathrm{~mm}$ ) per mouse analyzed. Nissl-stained and NeuNstained brain sections were photographed by a Leica DFC295camera coupled to a Leica DM IRE2 microscope with Leica Application Suite Version 4.1.0 image analysis software (Leica Microsystems).

\section{Enzyme-Linked Immunosorbent Assay for A $\beta$ Detection}

Endogenous mouse $A \beta$ levels were determined using the DELFIA Double Capture (Perkin Elmer, Melbourne, Australia) enzyme-linked immunosorbent assay (ELISA), as previously described [20]. Plates were coated with G210 (for $\left.\mathrm{A} \beta_{40}\right)$ antibody, then blocked with $0.5 \%(\mathrm{w} / \mathrm{v})$ casein/PBS buffer ( $\mathrm{pH}$ 7.4). After washing the plates with buffer containing PBS/Tween-20 (PBST) $0.05 \%$, 1E8-biotin (epitope $\mathrm{A} \beta 17-22)$ was diluted in $0.25 \%$ casein/PBST $(0.025 \%)$ and added to the wells. $A \beta_{1-40}$ peptide standards (Keck ERI Amyloid Laboratory, Oxford, CT, USA), diluted in $0.25 \%$ casein/PBST ( $0.025 \%)$ and sample [15 $\mu 1$ of brain homogenate $(1 \%$ sodium dodecyl sulfate/PBS) diluted into $185 \mu \mathrm{l}$ $0.25 \%$ casein/PBST $(0.025 \%)$ ] were assayed in triplicate and incubated overnight at $4{ }^{\circ} \mathrm{C}$. The plates were washed, labeled with europium, streptavidin added, and then developed with enhancement solution. Analysis was carried out using the Wallac Victor2 1420 Multilabel Plate Reader (Perkin Elmer) with excitation at $340 \mathrm{~nm}$ and emission at $613 \mathrm{~nm}$.

\section{Western Blot}

Samples from each experiments were homogenized in PBS (pH 7.4) with ethylenediaminetetraacetic acid-free protease inhibitor cocktail (1:50; Roche, Indianapolis, IN, USA)+ phosphatase inhibitors I and II (1:1000) and centrifuged at $40,000 \times \mathrm{g}$ for $30 \mathrm{~min}$. Protein concentration was determined by BCA protein assay (Pierce, Rockford, IL, USA). Aliquots of homogenate with equal protein concentrations were separated in 4-12\% bis-Tris gels with NuPAGE MES running buffer (Invitrogen, Carlsbad, CA, USA), and transferred to nitrocellulose membranes by iBlot (Invitrogen). The membranes were blocked with milk (5\% w/v) and probed with appropriate primary and secondary $\mathrm{IgG}$-horseradish peroxidase conjugated antibodies (Dako, Glostrup, Denmark). Enhanced chemiluminescence detection system (GE Healthcare, Little Chalfont, UK) was used for development 
and Fujifilm LAS-3000 for visualization (Fujifilm, Tokyo, Japan). Densitometry quantification of immunoreactive signals was performed by Image J (1.49 m; National Institutes of Health) and normalized to the relative amount of $\beta$-actin and expressed as a percentage of the mean of the control group. The following antibodies were used: anti- $\beta$-actin (Sigma, St. Louis, MO, USA); 22C11 (in house); anti-tau (Dako); anti-pTau396 (Invitrogen); 1E8 (in house); WO2 (in house).

\section{Metal Analysis}

Metal content was measured as previously described [11]. Briefly, samples from each experimental condition were freeze dried and then re-suspended in $65 \%$ nitric acid (Suprapur; Merck, Darmstadt, Germany) overnight. The samples were then heated for $20 \mathrm{~min}$ at $90^{\circ} \mathrm{C}$, and the equivalent volume of $\mathrm{H}_{2} \mathrm{O}_{2}$ ( $30 \%$ Aristar; $\left.\mathrm{BDH}\right)$ was added for further 15 min incubation at $70{ }^{\circ} \mathrm{C}$. The samples were diluted in double-distilled water and assayed by inductively coupled plasma mass spectrometer (Agilent 7700; Agilent Technologies, Santa Clara, CA, USA). Each sample was measured in triplicate and the concentrations determined from the standard curve were normalized to tissue wet weight.

\section{Statistics}

Statistical analysis was carried out in Prism 6 (GraphPad Software Inc., La Jolla, CA, USA). All tests were 2-tailed, with the level of significance set at 0.05 . Detailed tests used in each experiment are described in the text.

\section{Results}

\section{Three-Month-Old Tau KO Mice Are Resistant to A $\beta$ Toxicity}

To test the role of tau ablation against $\mathrm{A} \beta$ peptide toxicity, we performed bilateral intrahippocampal CA1 injection of $A \beta$ oligomer to tau $\mathrm{KO}$ and background (C57/B16) mice aged 3-5 months [8, 21]. This animal model has been used widely to test drug candidates for $\mathrm{AD}$ and has been consistently shown to induce cognitive impairment and neurodegeneration [21-24]. There were no cognition deficits using NORT (duration of sniffing novel object) apparent 1 week after the injection of $A \beta_{1-42}$ (Fig. 1a). Wild type (WT) mice developed cognitive impairment on NORT at 3 weeks postintoxication (Fig. 1b; $p=0.033,2$-tailed $t$ test), which was maintained by

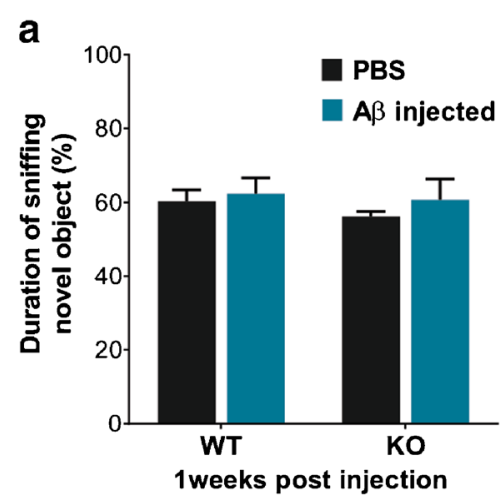

d

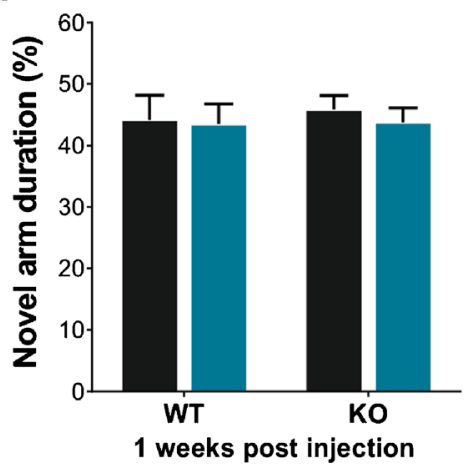

b

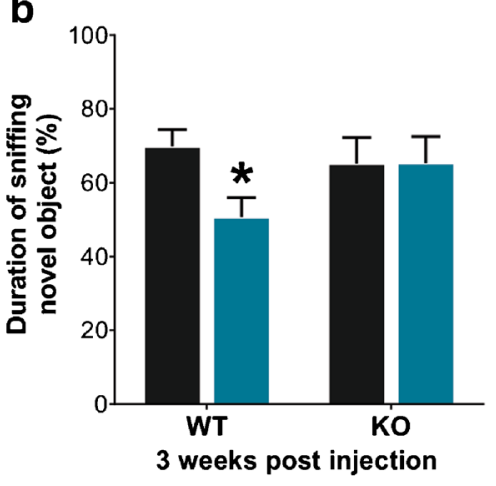

e

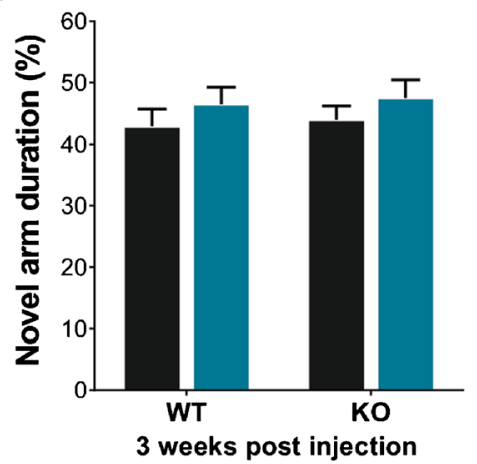

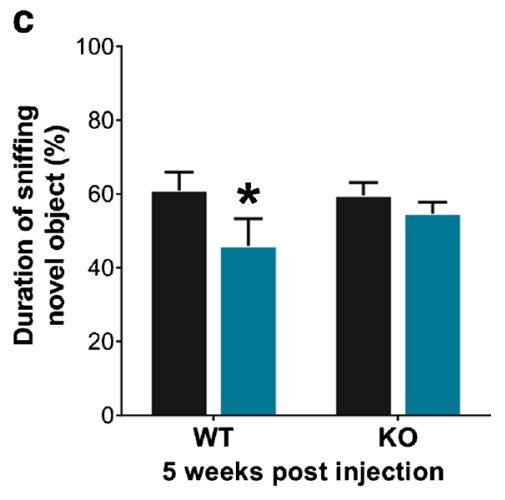

f

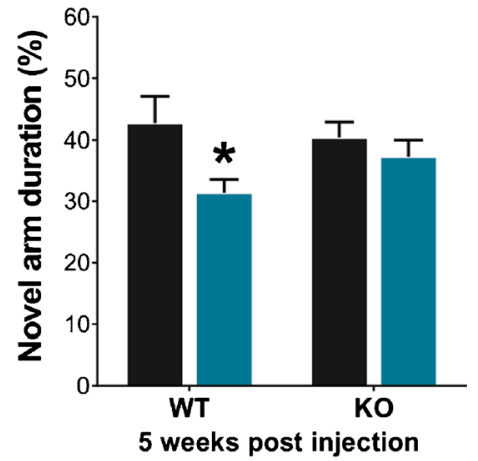

Fig. $1 A \beta$ injection impairs cognitive function of 3-month-old wild-type (WT) but not tau knockout $(\mathrm{KO})$ mice. $(\mathrm{a}-\mathrm{c})$ Mice were injected with 1 dose of human $\mathrm{A} \beta_{1-42}$ oligomer ( $\sim 0.9 \mu \mathrm{g}$ per mouse), and cognitive functions were measured by NORT (duration of sniffing novel object) (a) 1 week, (b) 3 weeks, or (c) 5 weeks after surgery. (d-f) Y-maze test for cognition after $A \beta$ injection and incubation (d) 1 week, (e) 3 weeks, or (f) 5 weeks after surgery. $\mathrm{n}$ [WT, phosphate-buffered saline (PBS) sham] $=6$; $\mathrm{n}(\mathrm{WT}, \mathrm{A} \beta)=7 ; \mathrm{n}(\operatorname{tau} \mathrm{KO}, \mathrm{PBS})=5 ; \mathrm{n}(\operatorname{tau} \mathrm{KO}, \mathrm{A} \beta)=7 .{ }^{*} p<0.05$ versus sham-injected WT mice. Data are means \pm SEM 
5 weeks (Fig. 1c; $p=0.050,2$-tailed $t$ test). WT mice were unimpaired in the Y-maze (duration in novel arm) at 1 (Fig. 1d) and 3 (Fig. 1e) weeks postinjection, but were impaired after 5 weeks (Fig. 1f; $p=0.041$, 2-tailed $t$ test).

In contrast, $A \beta_{1-42}$ injection had no impact in either cognitive test of 3-month-old tau $\mathrm{KO}$ mice for the duration of the experiment (Fig. 1a-f), indicating that $\mathrm{A} \beta$-induced memory loss is mediated by tau. Vehicle-treated tau KO mice were not impaired compared with WT mice (Fig. 1a-f), which reinforces our report and other findings that young tau $\mathrm{KO}$ mice have normal cognitive function $[5,6,13]$.

We analyzed hippocampal neuronal cell loss caused by $\mathrm{A} \beta_{1-42}$ injection in 3-month-old mice, using a specific neuronal stain (Nissl stain) (Fig. 2a-c). In WT mice injected with $\mathrm{A} \beta_{1-42}$ into $\mathrm{CA} 1$, the area of neurons in the CA1 region was significantly reduced compared with sham-injected mice [Fig. 2b; $-40 \%, p<0.001,2$-way analysis of variance (ANOVA) with Tukey post-hoc test], but was attenuated in tau KO mice ( $+35 \%$ compared with A $\beta$-injected WT mice; $p=0.005$ ). We observed no loss of hippocampal neurons in tau KO mice injected with $A \beta_{1-42}$ compared with vehicle-treated tau KOs $(p=0.7064)$, and no difference between shaminjected WT and tau KO mice $(p=0.637)$. Similar results were found in dentate gyrus (DG) region (a region with no direct injection) (Fig. 2c), where $A \beta_{1-42}$ injection in CA1 resulted in a significant reduction of neuronal area in WT mice $(-25 \%$, $p<0.001,2$-way ANOVA with Tukey post-hoc test) that was largely rescued by tau ablation $(+20 \%$, compared with $\mathrm{A} \beta$ injected WT mice; $p=0.009$ ).

Similar results were observed by NeuN staining (Fig. 3ac), an alternative stain for neurons that better distinguishes

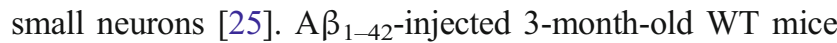
exhibited a thinner hippocampal layer in both the CA1 and DG areas (Fig. 3a), a feature that was not seen in sham-treated WT hippocampi. Quantification of the stained area revealed a significant reduction in both CA1 (Fig. $3 b ;-37 \%, p<0.001$, 2 -way ANOVA with Tukey post-hoc test) and DG (Fig. 3c; $-32 \%, p<0.001,2$-way ANOVA with Tukey post-hoc test) area of $A \beta_{1-42}$ injected WT mice compared with shaminjected WT mice. Sham-injected tau KO mice showed no differences compared with WT mice in the areas of both CA1 $(p=0.973)$ and DG $(p=0.928)$. While A $\beta$-injected tau $\mathrm{KO}$ mice showed a significant reduction in the neuronal area of CA1 (Fig. $3 \mathrm{~b} ;-17 \%, p=0.008$ ), the losses in the CA1 region were attenuated compared with WT mice $(p=0.003)$. The DG of tau KO mice was not significantly reduced in
Fig. $2 A \beta$ injection reduces hippocampal neuronal area (Nissl staining) of 3-month-old wildtype (WT) but not tau knockout (KO) mice. (a) Representative images of the hippocampus (Hippo), CA1 region, and dentate gyrus (DG) region from treated mice. Scale bars: $250 \mu \mathrm{m}$ for $5 \times$, and $50 \mu \mathrm{m}$ for $40 \times$. (b, c) Quantification of neuronal area in (b) CA1 and (c) DG regions. $n$ [WT, phosphate-buffered saline $(\mathrm{PBS})]=6 ; \mathrm{n}(\mathrm{WT}, \mathrm{A} \beta)=7$; $\mathrm{n}($ tau knockout, $\mathrm{PBS})=5 ; \mathrm{n}($ tau knockout, $\mathrm{A} \beta)=7 . * * * p<0.001$ versus sham-injected WT mice; ${ }^{\# \#} p<0.01$ versus $\mathrm{A} \beta$-injected WT mice; ${ }^{@} p<0.05$ versus shaminjected tau KOT mice . Data are means \pm SEM

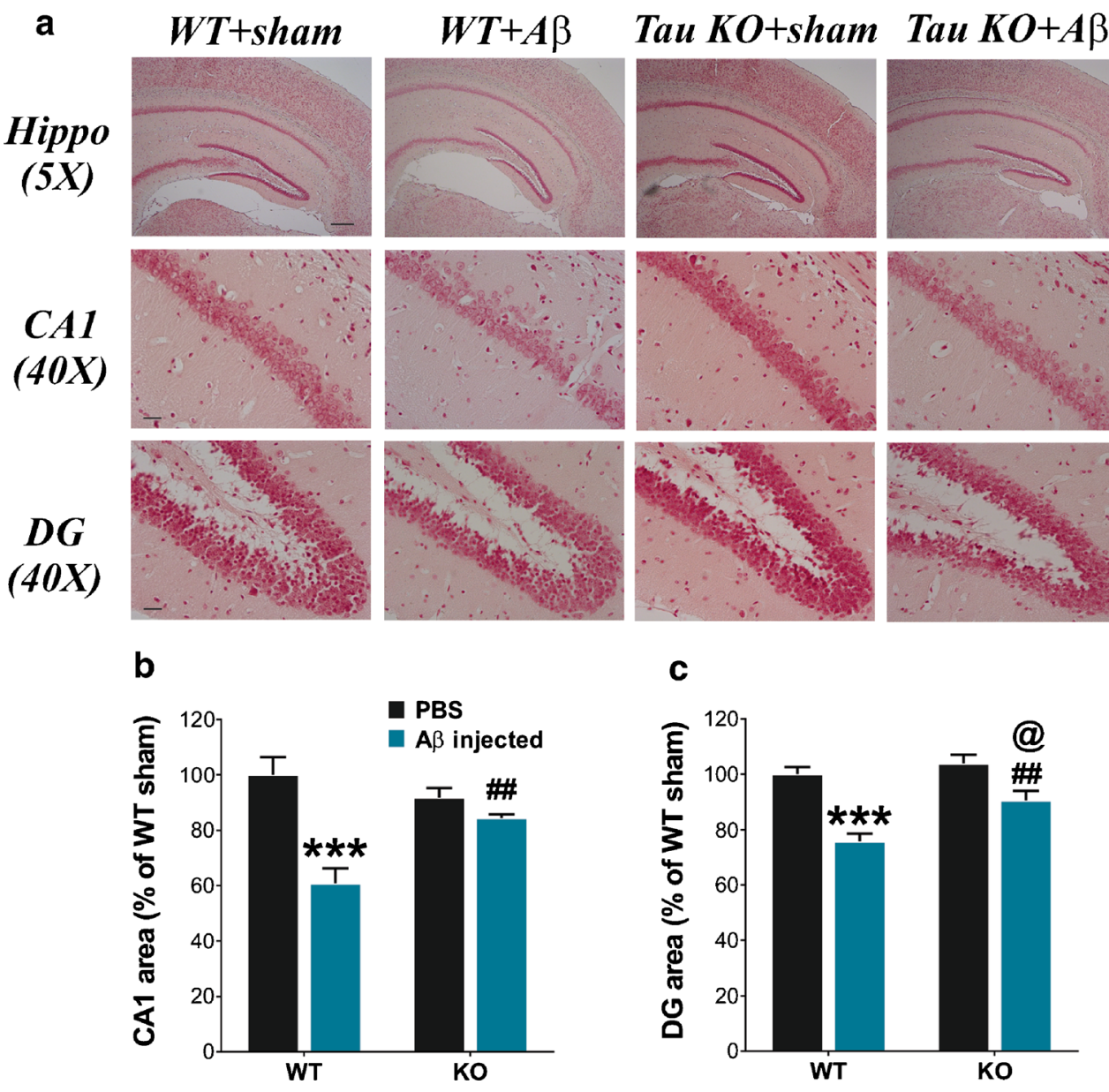


Fig. $3 \mathrm{~A} \beta$ injection reduces hippocampal neuronal area (NeuN staining) of 3-month-old wild-type (WT) but not tau knockout (KO) mice. (a) Representative images of the hippocampus (Hippo), CA1 region, and dentate gyrus (DG) region from treated mice. Scale bars: $250 \mu \mathrm{m}$ for $5 \times$ and $50 \mu \mathrm{m}$ for 40×. (b, c) Quantification of neuronal area in (b) CA1 and (c) DG regions. $n$ [WT, phosphatebuffered saline $(\mathrm{PBS})]=6 ; \mathrm{n}(\mathrm{WT}$, $\mathrm{A} \beta)=7$; $($ tau knockout, PBS $)=$ $5 ; \mathrm{n}($ tau knockout, $\mathrm{A} \beta)=7$. $* * * p<0.001$ versus shaminjected WT mice; ${ }^{\# \#} p<0.01$ versus $\mathrm{A} \beta$-injected WT mice; @@ $p<0.01$ versus sham-injected tau KO mice. Data are means \pm SEM a

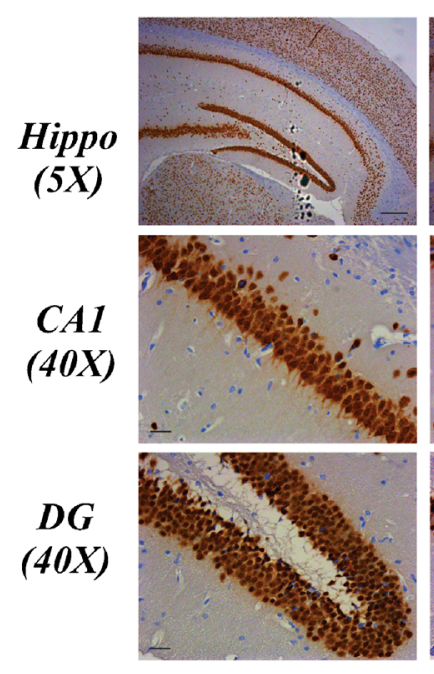

b

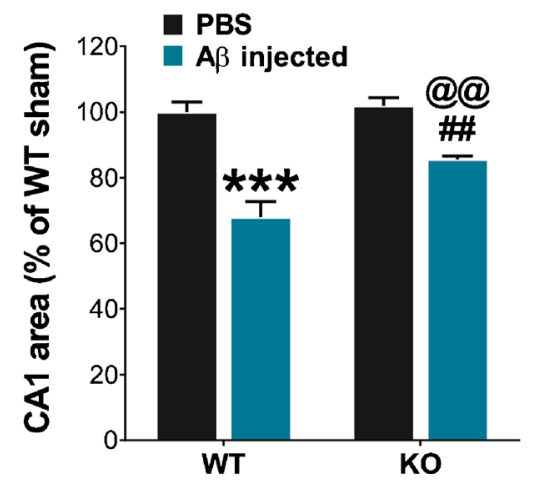

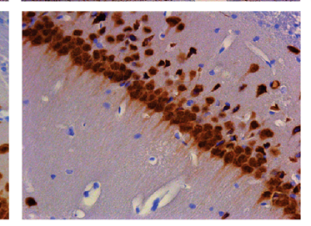

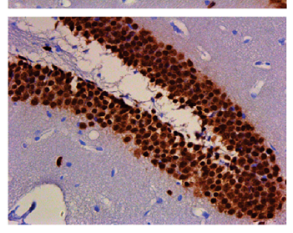

Tau $\mathrm{KO}+$ sham
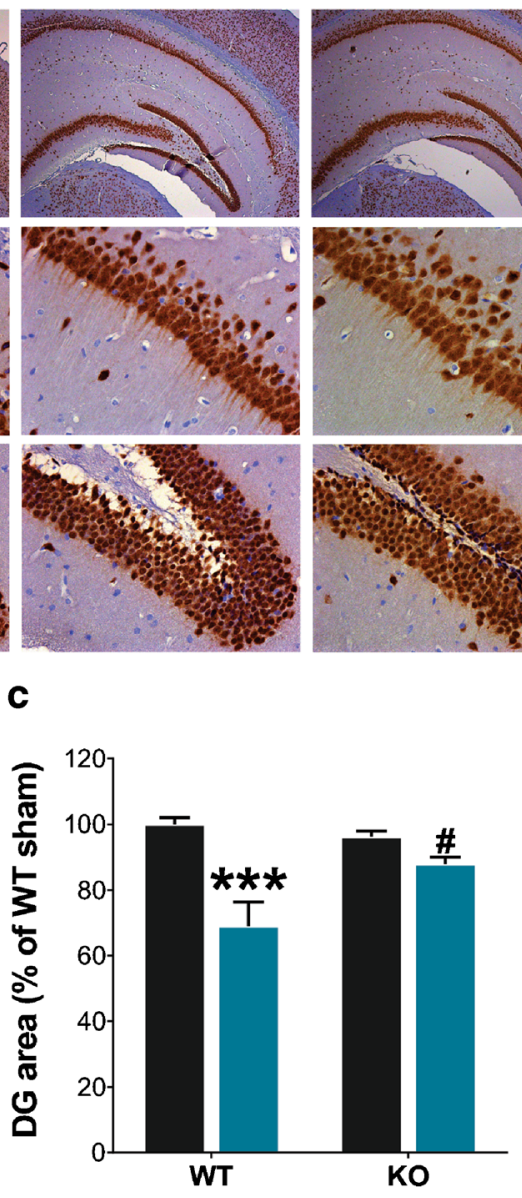

Tau $\mathrm{KO}+\boldsymbol{A} \beta$

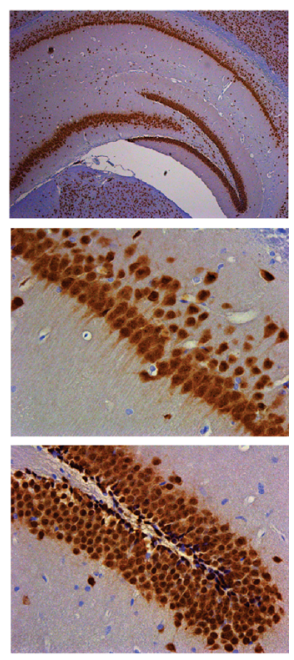

\section{C}

response to A $\beta$-injection, while the DG area of intoxicated WT mice was significantly decreased compared with tau KO mice ( $p=0.018$ ). In summary, both Nissl and NeuN staining of the hippocampal region revealed that 3-month-old tau KO mice are protected against $A \beta$ neurotoxicity, which may underlie the resistance to cognitive decline induced by $A \beta$ injection seen in Fig. 1.

It was previously reported that $A \beta$ injection might induce plaque-like structures in transgenic mouse overexpressing APP [26]. In our hands, we found no evidence that one-off human $A \beta$ injection causes endogenous mouse amyloid aggregation or deposition. Indeed, we found no apparent staining of $A \beta$ in the hippocampus of $A \beta$-injected mice, regardless of the genotype by $1 \mathrm{E} 8$ immunostaining (Fig. 4a). The lack of an immunosignal suggested that no residual human $A \beta$ persisted after 5 weeks of injection, and it is welldocumented that mouse $\mathrm{A} \beta$ cannot be detected by $1 \mathrm{E} 8 \mathrm{immu}-$ nostaining [27]. Western blot with WO2 antibody confirmed the absence of human $A \beta$ data not shown, and by ELISA we found no differences of mouse $A \beta$ between WT and tau KO mice, or between sham- and $A \beta$-injected groups (Fig. $4 b$ ). Interestingly, we found that APP (detected by $22 \mathrm{C} 11$ ) was significantly elevated in the hippocampus of $A \beta$-injected
WT mice (Fig. 4c, d; $+20 \%, p=0.027$, 2-tailed $t$ test), a change that was absent in $\mathrm{A} \beta$-injected tau $\mathrm{KO}$ mice.

\section{Twelve-month-old Tau KO Mice are Resistant to $A \beta$ Toxicity}

Previous reports using APP transgenics to overexpress A $\beta$ in a tau KO background showed that the neuroprotective effect of tau ablation only occurred in young mice (3-5 months old) $[5,6]$, whereas 12 -month-old APP/tau ${ }^{-/-}$mice expressed more severe neurodegeneration than APP transgenic mice [15]. We therefore tested 12-month-old WT and tau KO mice using the $A \beta$ injection challenge. As we previously reported [13], 12-month-old tau KO mice in a C57/B16 background showed no sign of cognitive impairment, unlike the tau KO mice in a B16/129sv background, which express cognitive decline $[11,13]$. In the current study, we confirmed those observations using both the NORT (Fig. 5a-c) and Y-maze tests (Fig. 5d-f). A $\beta$ injection impaired the cognition of 12 month-old WT mice, evidenced by a reduction in frequency of sniffing novel objects in NORT ( $p=0.018,2$-tailed $t$ test) 3 weeks postinjection (Fig. $5 b$ ), and reduction in time spent in the novel arm in the Y-maze test ( $p=0.026$, 2-tailed $t$ test) 
Fig. 4 Human $A \beta$ injection elevates amyloid precursor protein (APP) but does not change endogenous murine $A \beta$ in the hippocampus (Hippo) of 3month-old wild-type (WT) mice (a) Representative images of the hippocampus and CA1 region from treated mice stained with $\mathrm{A} \beta$ antibody $1 \mathrm{E} 8$. Scale bars: $250 \mu \mathrm{m}$ for $5 \times$ and $50 \mu \mathrm{m}$ for 40×. (b) Enzyme-linked immunosorbent assay results of mouse $\mathrm{A} \beta_{1-40}$ in the

hippocampus of treated mice. $n$ [WT, phosphate-buffered saline $(\mathrm{PBS})]=6 ; \mathrm{n}(\mathrm{WT}, \mathrm{A} \beta)=7$; $\mathrm{n}(\mathrm{tau}$ knockout, $\mathrm{PBS})=5 ; \mathrm{n}$ (tau knockout, $A \beta$ ) $=7$. (c)

Representative Western blots of APP and actin in the hippocampus of mice. (d) Densitometry analysis of (c), normalized to $\beta$-actin. $n=6$ per group except $\mathrm{n}$ (tau knockout, PBS) $=5 .{ }^{*} p<0.05$ versus shaminjected WT mice. Data are means \pm SEM a

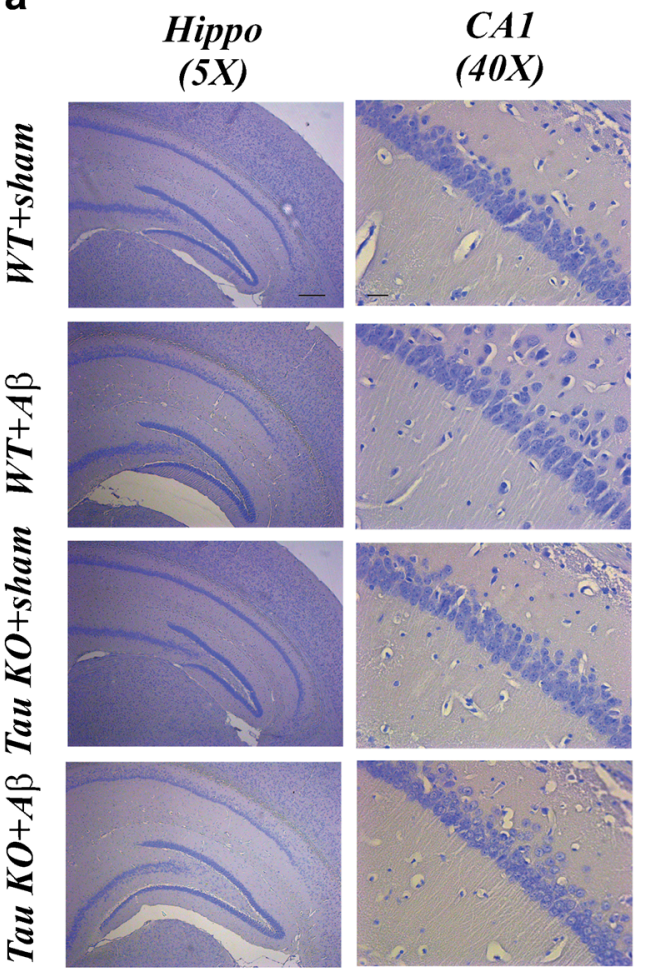

b
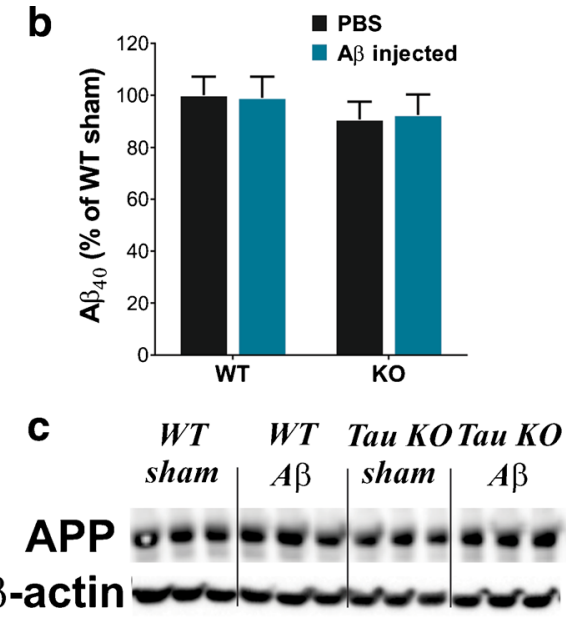

d

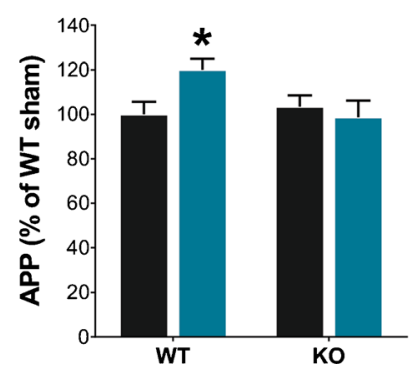

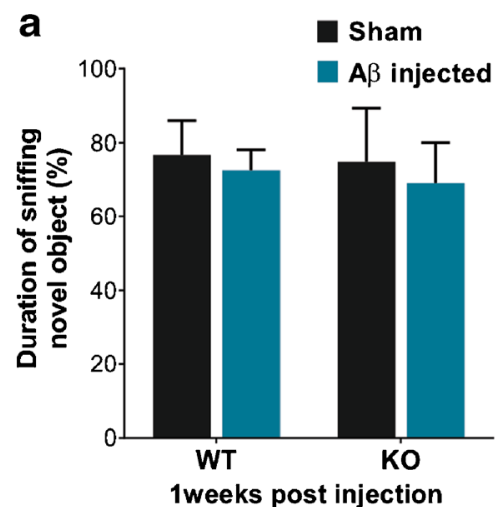

d

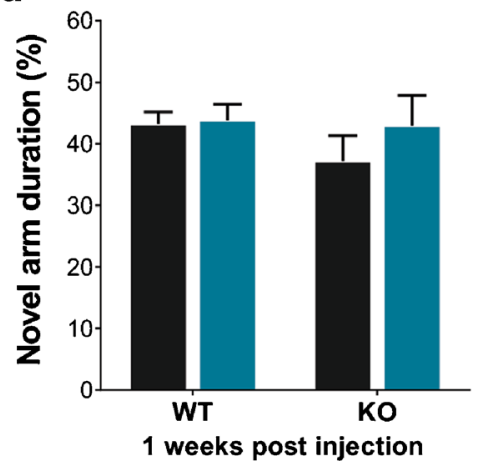

b

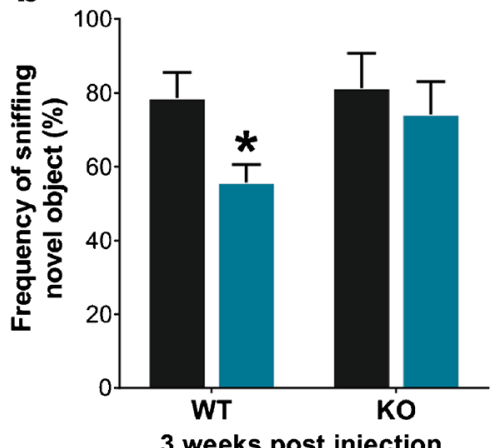

3 weeks post injection

e

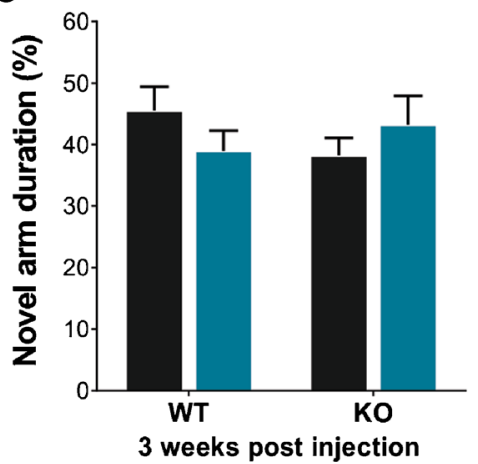

C

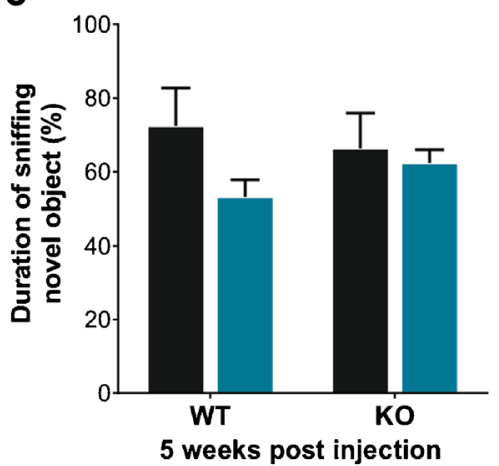

f

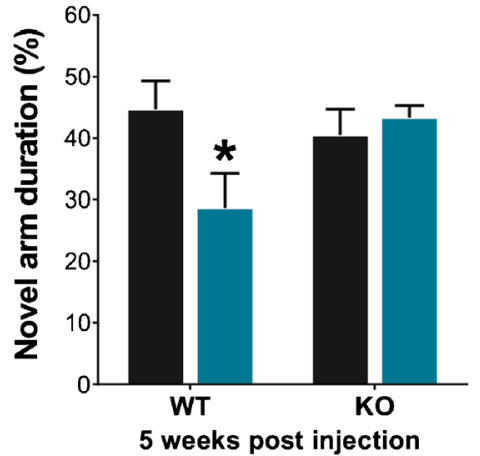

Fig. $5 \mathrm{~A} \beta$ injection impairs cognitive function of 12-month-old wildtype (WT) mice but not tau knockout (KO) mice. (a-c) Mice were injected with 1 dose of human $\mathrm{A} \beta_{1-42}$ oligomer, and cognitive functions were measured by NORT (duration of sniffing novel object) (a) 1 week, (b) 3 weeks, or (c) 5 weeks after surgery. (d-f) Y-maze test for consequences of $A \beta$ injection (d) 1 week, (e) 3 weeks, or (f) 5 weeks after surgery. $\mathrm{n}$ (WT, phosphate-buffered saline) $=9 ; \mathrm{n}(\mathrm{WT}, \mathrm{A} \beta)=10 ; \mathrm{n}$ $($ tau knockout, phosphate-buffered saline $)=5 ; \mathrm{n}($ tau knockout, $\mathrm{A} \beta)=8$. $* p<0.05$ versus sham-injected WT mice. Data are means \pm SEM 
5 weeks postinjection (Fig. 5 f). These results were similar to our findings with younger (3-month-old) mice (Fig. 1b, f). Also, consistently, $\mathrm{A} \beta$ injection of tau $\mathrm{KO}$ mice induced no changes in the behavioral tests (Fig. 5b, c, f), indicating that tau ablation prevented $A \beta$-induced memory deficits, even at 12 months of age.

Nissl staining of the hippocampus was consistent with the neuroprotective effect of tau $\mathrm{KO}$ against $\mathrm{A} \beta$-induced neuronal death (Fig. 6a-c). In 12-month-old WT mice, $A \beta$ injection induced a significant lesion $(-15 \%, p=0.005,2$-way ANOVA with Tukey post-hoc test) in the CA1 region, but this was smaller than the lesion induced in mice aged 3 months ( $-40 \%$; Fig. $2 b)$. Similar to the results in younger mice, 12month-old tau $\mathrm{KO}$ mice were relatively protected against atrophy of the CA1 induced by $\mathrm{A} \beta$ injection (Fig. $6 \mathrm{~b} ; p=0.015$ ). The DG showed no sign of neuronal loss in any group (Fig. 6c).

Similar to the findings in 3-month-old mice, 5 weeks after the $A \beta$ injection, no human $A \beta$ was detected in the hippocampus by Western blot (WO2 antibody, data not shown), and no changes in mouse $A \beta$ detected by ELISA in both 12month-old WT and tau KO mice (Fig. 7a). APP levels were markedly elevated in 12-month-old WT mice 5 weeks after $\mathrm{A} \beta$ injection (Fig. $7 \mathrm{~b}, \mathrm{c} ;+40 \%, p=0.036$, two-way ANOVA

Fig. 6 A $\beta$ injection reduces hippocampal neuronal area (Nissl staining) of 12-month-old wildtype (WT) mice but not tau knockout (KO) mice. (a) Representative images of the hippocampus (Hippo), CA1 region, and dentate gyrus (DG) region from treated mice. Only images of CA1 region and DG region were used for quantification. Scale bars: $250 \mu \mathrm{m}$ for $5 \times$ and $50 \mu \mathrm{m}$ for $40 \times$. (b, c) Quantification of neuronal area in (b) CA1 and (c) DG regions. Detailed methods for quantification were described in the "Methods". n (WT, phosphate-buffered saline $)=9 ; n$ (WT, A $\beta)=10$; n (tau knockout, phosphate-buffered saline) $=5 ; \mathrm{n}$ (tau knockout, $\mathrm{A} \beta$ ) $=8 .{ }^{* *} p<0.01$ versus sham-injected WT mice; ${ }^{\#} p<0.05$ versus A $\beta$-injected WT mice. Data are means \pm SEM with Tukey post-hoc test), but this elevation was absent in tau KO mice $(p=0.937)$. A trend towards increased APP in control tau KO mice compared with WT mice was noted (+20\%).

\section{Increased Hippocampal Iron Induced by $\mathbf{A} \beta$}

In $\mathrm{AD}$ pathology, metals such as iron, copper, and zinc interact with A $\beta$ [28]. APP translation is promoted by iron [29, 30], and we observed increased APP levels in A $\beta$-injected mice (Figs. $4 \mathrm{~d}$ and $7 \mathrm{c}$ ), consistent with iron elevation. Indeed, in the hippocampus of $A \beta$-injected 3-month-old WT mice, iron levels 5 weeks after the insult were elevated compared with sham-injected mice (Fig. $8 \mathrm{a} ;+20 \%, p=0.031$, 2-tailed $t$ test). $\mathrm{A} \beta$ injected into the hippocampi of tau $\mathrm{KO}$ mice did not cause iron elevation, indicating that tau is involved in iron accumulation. Neither copper (Fig. 8b) nor zinc (Fig. 8c) were altered by $\mathrm{A} \beta$ injection. Iron was increased with age ( 3 months $v s$ 12 months, $+35 \%, p=0.002$, 2-tailed $t$ test), consistent with previous findings [31]. Further iron accumulation was observed in $A \beta$-injected WT mice compared with shaminjected mice at 12 months of age (Fig. 8d; $+13 \%, p=$ 0.033 , 2-tailed $t$ test) but, again, not in age-matched tau KO mice, consistent with tau being involved in iron regulation. Hippocampal copper and zinc levels also increased with age

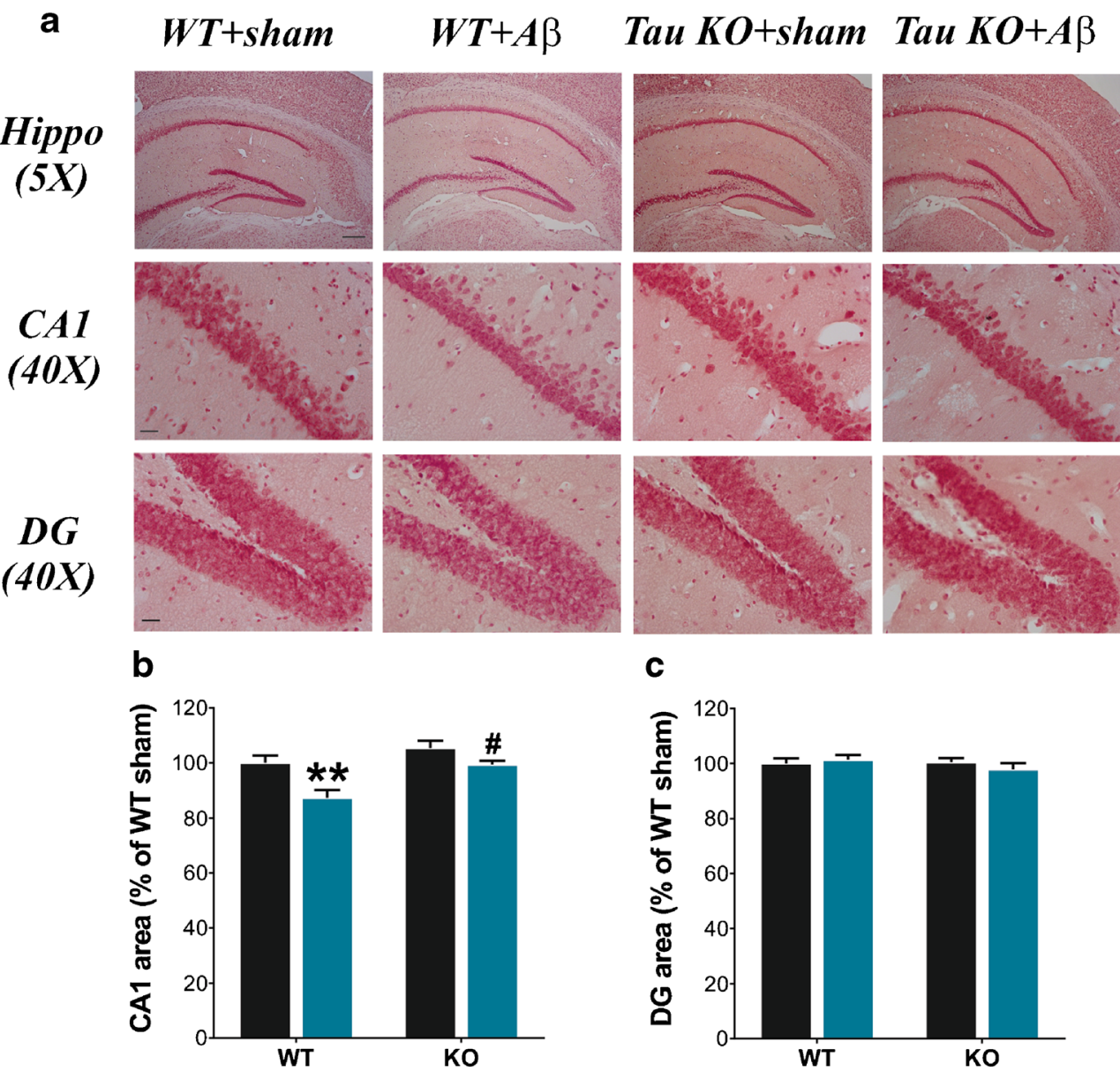


a

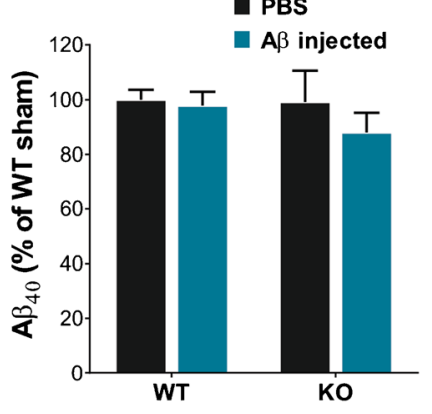

b

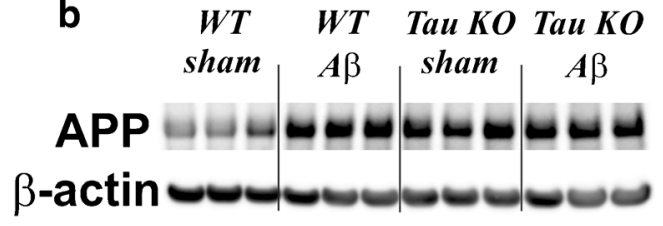

C

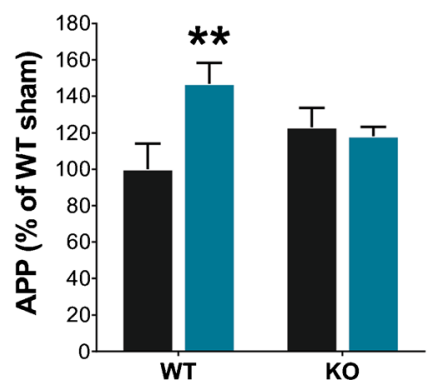

Fig. 7 Human $A \beta$ injection elevates amyloid precursor protein (APP) but does not change endogenous murine $A \beta$ in the hippocampus of 12month-old wild-type (WT) mice (a) Enzyme-linked immunosorbent assay results of mouse $A \beta_{1-40}$ in the hippocampus of treated mice. $n$ [WT, phosphate-buffered saline (PBS)]=9; n (WT, A $\beta)=10$; n (tau knockout, PBS) $=5$; n (tau knockout, $A \beta)=8$. (b) Representative Western blots of APP and actin in the hippocampus of mice. (c) Densitometry analysis of (b), normalized to $\beta$-actin. $n=6$ per group except $\mathrm{n}$ (tau knockout, PBS) $=5 .{ }^{* *} p<0.01$ versus sham-injected WT mice. Data are means \pm SEM

(3 months vs 12 months; for copper, $+20 \%, p=0.039$; for zinc, $+36 \%, p=0.001$, 2-tailed $t$ test) but were unaffected by $\mathrm{A} \beta$ injection in 12-month-old mice (Fig. 8e, f).

\section{Tau and Phosphorylated Tau Levels in $A \beta$-Injected Hippocampus}

We previously showed that tau prevents brain iron accumulation [11]. Therefore, we considered whether in $A \beta$-injected models, the observed iron accumulation might be due to a decrease in soluble tau protein in response to intoxication (Fig. 8a, d). To test this hypothesis, we measured soluble tau content in the hippocampus and found that 5 weeks after the challenge there was markedly less hippocampal tau protein in the A $\beta$-injected 3-month-old WT mice compared with shaminjected mice (Fig. 9a, b; $-50 \%, p=0.004$, 2-tailed $t$ test). A $\beta$ injection also resulted in the striking hyperphosphorylation of the remaining tau at Ser396 (Fig. 9a, c; $+135 \%, p=0.002$, 2tailed $t$ test), a site linked with AD pathology, confirming a response to $A \beta$ challenge that has been previously reported [1, $23,32]$. An attenuated (but significantly) decrease in tau was observed in 12-month-old WT mice injected with $A \beta$ (Fig. 9d, e; $-19 \%, p=0.029,2$-tailed $t$ test), but the relative elevation in tau phosphorylated at Ser396 was not significant (Fig. 9d, f).

\section{Discussion}

$A \beta$ injection was previously reported to trigger intracellular $\mathrm{A} \beta$ aggregation in transgenic animals, and nonhuman primates, both of which express human sequence $A \beta[33,34]$. Mice and rats have a different sequence of $\mathrm{A} \beta$ that does not precipitate, even in the presence of zinc [35]. We found no evidence for endogenous mouse $A \beta$ aggregation in the human $\mathrm{A} \beta$ injection model (Figs. $4 \mathrm{a}, \mathrm{b}$ and $7 \mathrm{a}$ ), consistent with previous findings [36, 37].

We observed that $A \beta$ injection caused cognitive deficits that persisted even after the peptide was cleared from the injection site. This suggests that downstream intracellular toxic events propagate the toxicity of $A \beta$ after the initial insult, and is in accord with the human disease progression where $A \beta$ is elevated decades before symptom onset [38]. We found that one of the persistent effects of $A \beta$ intoxication was increased local iron levels (Fig. 8), which is also pathology of $\mathrm{AD}[28,39]$. Lowering brain iron has been shown to reduce memory deficits and neuronal loss in $\mathrm{AD}$ animal models and in a clinical trial [11, 14, 40-43]. We recently reported that elevated brain iron, as reflected by elevated cerebrospinal fluid ferritin levels, is associated with accelerated cognitive decline [44], highlighting the role of iron in $\mathrm{AD}$ progression. The current study raises the possibility that $\mathrm{A} \beta$ intoxication promotes toxic iron accumulation in the disease.

We previously found that tau reduction causes iron accumulation, which resulted in age- dependent neurodegeneration, manifesting in cognitive deficits and brain atrophy [11-13]. Tau KO mice have impaired neuronal iron efflux. Brain iron levels are unaffected in young tau $\mathrm{KO}$ mice, probably because of compensatory changes, but brain iron levels rise with age [31], and this rise is exaggerated in tau KOs where it contributes to gray matter atrophy [11]. Here, in an $\mathrm{A} \beta$ injection model, we found that cognitive deficits (Figs. 1 and 5) and neuron loss in the hippocampus (Figs. 2, 3 and 6) accompanied the persistent reduction of tau protein levels (Fig. 9) and concomitant iron accumulation (Fig. 8). Iron elevation as a consequence of $\mathrm{A} \beta$ toxicity, therefore, could be caused by the suppression of tau protein (without adequate compensatory changes to correct iron elevation). A role for tau in contributing to iron elevation after $A \beta$ injection is supported by our observation that iron levels did not rise in intoxicated tau $\mathrm{KO}$ mice. In tau $\mathrm{KO}$ mice (where the 

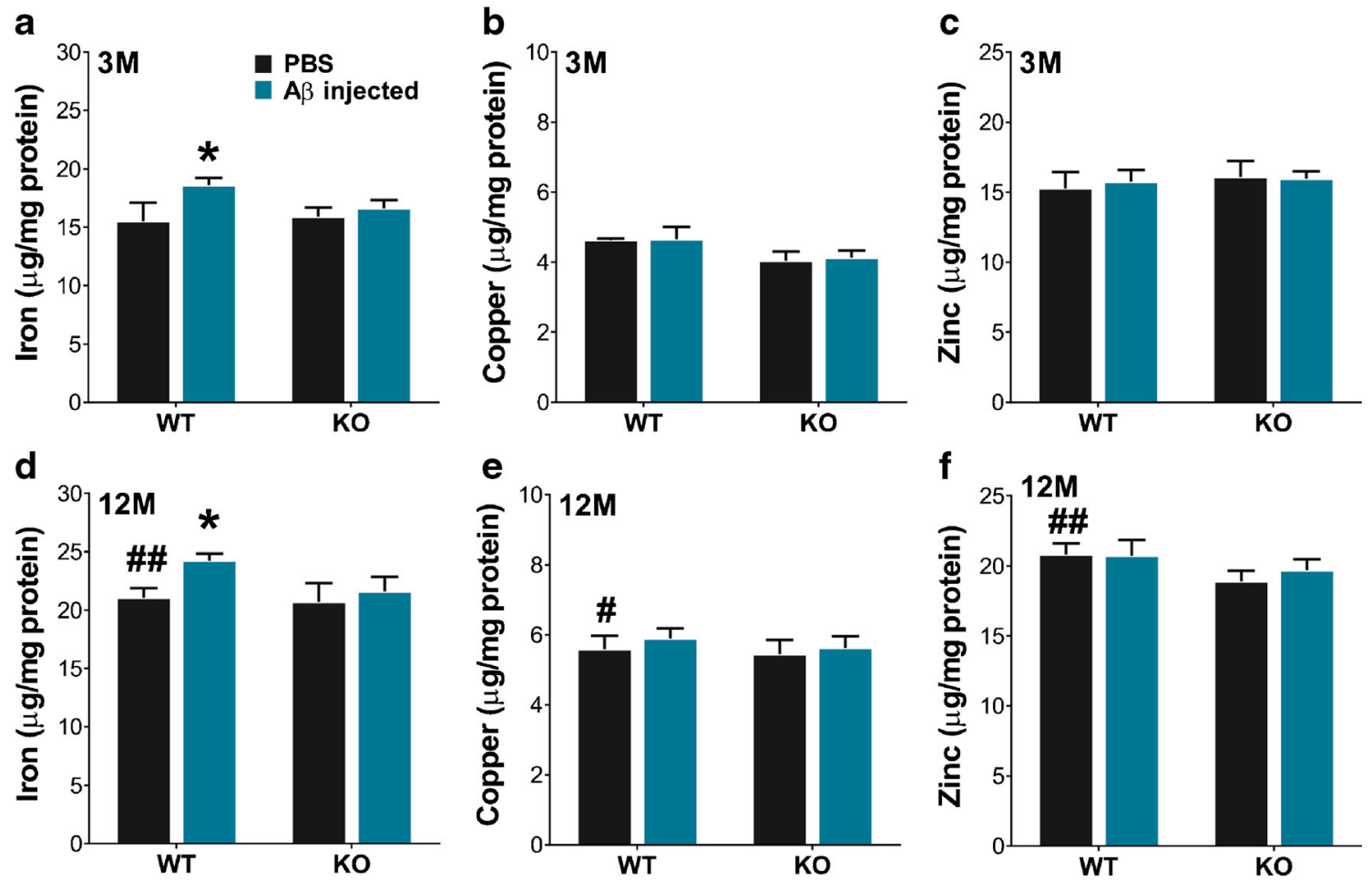

Fig. 8 Hippocampal metal levels in sham- and $A \beta$-injected wild-type (WT) and tau knockout (KO) mice. (a-c) Metal levels in hippocampus of treated 3-month-old mice. Significant elevation of (a) iron in the WT brain was found after $A \beta$ injection. The elevation is absent in tau KO mice injected with $A \beta$. No differences of (b) copper or (c) zinc were found in $A \beta$-treated mice compared with sham-treated mice. $n$ [WT, phosphate-buffered saline $(\mathrm{PBS})]=6$; $\mathrm{n}(\mathrm{WT}, \mathrm{A} \beta)=7$; $\mathrm{n}$ (tau knockout,

PBS) $=5 ; n$ (tau knockout, $A \beta$ )=7. (d) Iron, (e) copper, and (f) zinc levels in hippocampus of treated 12-month-old mice. $\mathrm{n}(\mathrm{WT}, \mathrm{PBS})=9$; $\mathrm{n}$ (WT, $\mathrm{A} \beta)=10 ; \mathrm{n}($ tau knockout, $\mathrm{PBS})=5 ; \mathrm{n}($ tau knockout, $\mathrm{A} \beta)=8$. The metal content was normalized by protein concentration in each tissue. ${ }^{*} p<0.05$ versus sham-injected age-matched WT mice. ${ }^{\#} p<0.05,{ }^{\# \#} p<0.01$ versus sham-injected 3-month-old WT mice. Data are means \pm SEM
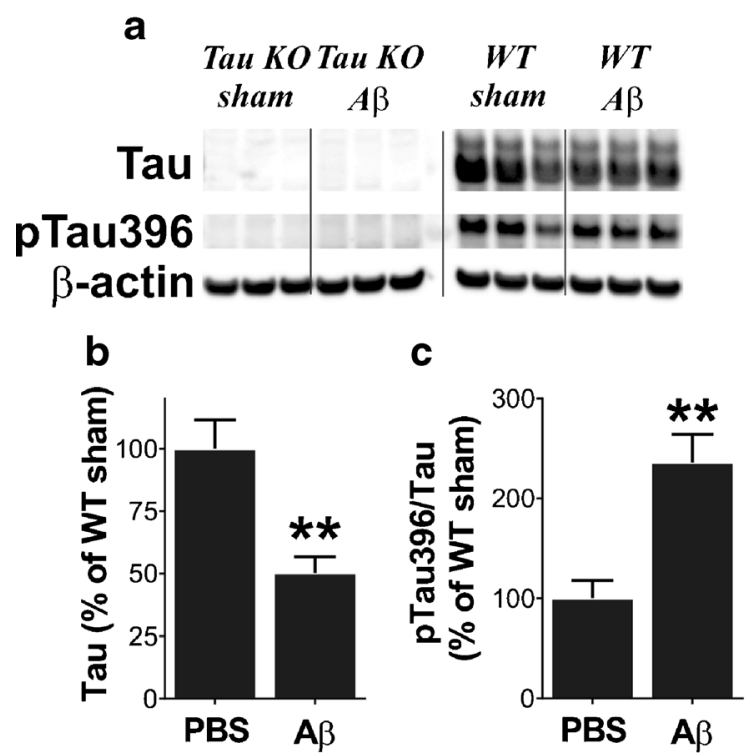

Fig. 9 Persistent suppression of soluble tau levels 5 weeks after $A \beta$ injection. (a) Representative Western blots of tau, pTau396, and actin in the hippocampus of 3-month-old mice. (b, c) Densitometry analysis for (b) tau and (c) tau/ptau396 ratio of (a), normalized to $\beta$-actin. (d) Representative Western blots of tau, pTau396, and actin in the

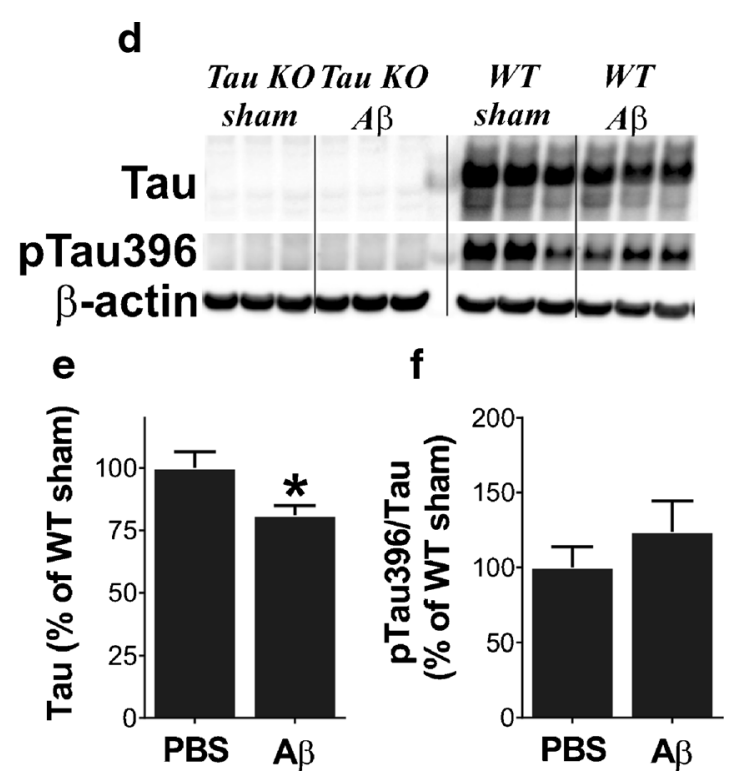

hippocampus of 12-month-old mice. (e, f) Densitometry analysis for (e) tau and (f) tau/ptau396 ratio of (d), normalized to $\beta$-actin. $n=6$ per group except $\mathrm{n}$ [tau knockout, phosphate-buffered saline (PBS)] $=5$. ${ }^{*} p<0.05$, $*^{* *}<0.01$ versus sham-injected WT mice. Data are means \pm SEM 
animal has benefitted from compensatory homeostatic changes since conception), iron was not elevated in response to $\mathrm{A} \beta$ injection because tau levels could not be acutely depressed.

In both 3-month-old (Fig. 4) and 12-month-old (Fig. 7) WT mice, an $A \beta$ injection induced a persistent (5-week) elevation in APP. This could reflect a homeostatic adjustment to hippocampal iron elevation. Iron induces the increased translation of APP [29], and is trafficked by tau to the neuronal surface where it stabilizes ferroportin to promote iron efflux $[11,45,46]$. As iron is still elevated at 5 weeks, clearly the increase in APP expression is insufficient to compensate fully for the perturbance. This would be consistent with the drop of tau being an upstream event induced by $\mathrm{A} \beta$, as tau $\mathrm{KO}$ neurons in culture also have a similar increased expression in APP, yet the APP does not reach the neuronal surface to stabilize ferroportin [11]. In tau $\mathrm{KO}$ mice, none of these downstream changes are possible as the tau-APP trafficking mechanism as a means of controlling cytoplasmic iron has been absent from conception.

Alternatively, or concurrently, increased tau phosphorylation after $A \beta$ intoxication might also contribute to the neurotoxicity we observed (which cannot occur in tau KO mice). In humans, abnormally phosphorylated tau but not amyloid can be detected as early as young adulthood [47], indicating a toxicity pathway for tau independent of $A \beta$. We only observed an increase in the ratio of phospho-tau to tau protein after $A \beta$ injection, not an increase in the total levels of phospho-tau. Taken together, our study supports therapeutic targeting of downstream effectors of $A \beta$ toxicity, such as phospho-tau or iron, which continue to propagate neurotoxicity after $A \beta$ has been cleared.

Acknowledgments This work was supported by funds from the Australian Research Council, the National Health and Medical Research Council (NHMRC) of Australia, the Cooperative Research Center for Mental Health, and the Alzheimer's Australia Dementia Research Foundation. The Florey Institute of Neuroscience and Mental Health acknowledges the strong support from the Victorian Government and, in particular, the funding from the Operational Infrastructure Support Grant.

Required Author Forms Disclosure forms provided by the authors are available with the online version of this rticle.

\section{References}

1. Liu T, Perry G, Chan HW, et al. Amyloid-beta-induced toxicity of primary neurons is dependent upon differentiation-associated increases in tau and cyclin-dependent kinase 5 expression. $\mathrm{J}$ Neurochem 2004;88:554-563.

2. Rapoport M, Dawson HN, Binder LI, Vitek MP, Ferreira A. Tau is essential to beta-amyloid-induced neurotoxicity. Proc Natl Acad Sci U S A 2002;99:6364-6369.
3. Vossel KA, Zhang K, Brodbeck J, et al. Tau reduction prevents A $\{$ beta $\}$-induced defects in axonal transport. Science 2010;330: 198.

4. Shipton OA, Leitz JR, Dworzak J, et al. Tau protein is required for amyloid \{beta\}-induced impairment of hippocampal long-term potentiation. J Neurosci 2011;31:1688-1692.

5. Roberson ED, Scearce-Levie K, Palop JJ, et al. Reducing endogenous tau ameliorates amyloid beta-induced deficits in an Alzheimer's disease mouse model. Science 2007;316:750-754.

6. Ittner LM, Ke YD, Delerue F, et al. Dendritic function of tau mediates amyloid-beta toxicity in Alzheimer's disease mouse models. Cell 2010;142:387-397.

7. Leroy K, Ando K, Laporte V, et al. Lack of tau proteins rescues neuronal cell death and decreases amyloidogenic processing of APP in APP/PS1 mice. Am J Pathol 2012;181:1928-1940.

8. Ahmed T, Van der Jeugd A, Blum D, et al. Cognition and hippocampal synaptic plasticity in mice with a homozygous tau deletion. Neurobiol Aging 2014;35:2474-2478.

9. Kimura T, Whitcomb DJ, Jo J, et al. Microtubule-associated protein tau is essential for long-term depression in the hippocampus. Philos Trans R Soc Lond B Biol Sci 2014;369:20130144.

10. Regan P, Piers T, Yi JH, et al. Tau phosphorylation at serine 396 residue is required for hippocampal LTD. J Neurosci 2015;35: 4804-4812.

11. Lei P, Ayton S, Finkelstein DI, et al. Tau deficiency induces parkinsonism with dementia by impairing APP-mediated iron export. Nat Med 2012;18:291-295.

12. Ma QL, Zuo X, Yang F, et al. Loss of MAP function leads to hippocampal synapse loss and deficits in the Morris Water Maze with aging. J Neurosci 2014;34:7124-7136.

13. Lei P, Ayton S, Moon S, et al. Motor and cognitive deficits in aged tau knockout mice in two background strains. Mol Neurodegener 2014;9:29.

14. Lei P, Ayton S, Appukuttan AT, et al. Clioquinol rescues Parkinsonism and dementia phenotypes of the tau knockout mouse. Neurobiol Dis 2015 Mar 18 [Epub ahead of print].

15. Dawson HN, Cantillana V, Jansen M, et al. Loss of tau elicits axonal degeneration in a mouse model of Alzheimer's disease. Neuroscience 2010;169:516-531.

16. Smith MA, Siedlak SL, Richey PL, et al. Tau protein directly interacts with the amyloid beta-protein precursor: implications for Alzheimer's disease. Nat Med 1995;1:365-369.

17. Duce JA, Tsatsanis A, Cater MA, et al. Iron-export ferroxidase activity of $\beta$-amyloid precursor protein is inhibited by zinc in Alzheimer's disease. Cell 2010;142:857-867.

18. Baleriola J, Walker CA, Jean YY, et al. Axonally synthesized ATF4 transmits a neurodegenerative signal across brain regions. Cell 2014;158:1159-1172.

19. Dawson HN, Ferreira A, Eyster MV, et al. Inhibition of neuronal maturation in primary hippocampal neurons from tau deficient mice. J Cell Sci 2001;114:1179-1187.

20. Li QX, Mok SS, Laughton KM, et al. Overexpression of Abeta is associated with acceleration of onset of motor impairment and superoxide dismutase 1 aggregation in an amyotrophic lateral sclerosis mouse model. Aging Cell 2006;5:153-165.

21. Sotthibundhu A, Sykes AM, Fox B, et al. Beta-amyloid(1-42) induces neuronal death through the p75 neurotrophin receptor. J Neurosci 2008;28:3941-3946.

22. Desbene C, Malaplate-Armand C, Youssef I, et al. Critical role of cPLA2 in Abeta oligomer-induced neurodegeneration and memory deficit. Neurobiol Aging 2012;33:1123 e1117-e1129.

23. Amini E, Nassireslami E, Payandemehr B, et al. Paradoxical role of PKA inhibitor on amyloidbeta-induced memory deficit. Physiol Behav 2015;149:76-85.

24. Moon M, Choi JG, Nam DW, et al. Ghrelin ameliorates cognitive dysfunction and neurodegeneration in intrahippocampal amyloid- 
beta1-42 oligomer-injected mice. J Alzheimers Dis 2011;23:147159.

25. Gittins R, Harrison PJ. Neuronal density, size and shape in the human anterior cingulate cortex: a comparison of Nissl and NeuN staining. Brain Res Bull 2004;63:155-160.

26. Stohr J, Watts JC, Mensinger ZL, et al. Purified and synthetic Alzheimer's amyloid beta (Abeta) prions. Proc Natl Acad Sci U S A 2012;109:11025-11030.

27. Li QX, Maynard C, Cappai R, et al. Intracellular accumulation of detergent-soluble amyloidogenic A beta fragment of Alzheimer's disease precursor protein in the hippocampus of aged transgenic mice. J Neurochem 1999;72:2479-2487.

28. Ayton S, Lei P, Bush AI. Biometals and their therapeutic implications in Alzheimer's disease. Neurotherapeutics 2015;12:109-120.

29. Rogers JT, Randall JD, Cahill CM, et al. An iron-responsive element type II in the 5'-untranslated region of the Alzheimer's amyloid precursor protein transcript. J Biol Chem 2002;277:4551845528.

30. Ayton S, Lei P, Hare DJ, et al. Parkinson's disease iron deposition caused by nitric oxide-induced loss of beta-amyloid precursor protein. J Neurosci 2015;35:3591-3597.

31. Maynard CJ, Cappai R, Volitakis I, et al. Gender and genetic background effects on brain metal levels in APP transgenic and normal mice: implications for Alzheimer beta-amyloid pathology. J Inorg Biochem 2006;100:952-962.

32. Götz J, Chen F, van Dorpe J, Nitsch RM. Formation of neurofibrillary tangles in P3011 tau transgenic mice induced by Abeta 42 fibrils. Science 2001;293:1491-1495.

33. Forny-Germano L, Lyra ESNM, Batista AF, et al. Alzheimer's disease-like pathology induced by amyloid-beta oligomers in nonhuman primates. J Neurosci 2014;34:13629-13643.

34. Rosen RF, Fritz JJ, Dooyema J, et al. Exogenous seeding of cerebral beta-amyloid deposition in betaAPP-transgenic rats. J Neurochem 2012;120:660-666.

35. Bush AI, Pettingell WH, Multhaup G, et al. Rapid induction of Alzheimer A beta amyloid formation by zinc. Science 1994;265: 1464-1467.

36. Jankowsky JL, Younkin LH, Gonzales V, et al. Rodent A beta modulates the solubility and distribution of amyloid deposits in transgenic mice. J Biol Chem 2007;282:22707-22720.
37. Levi O, Dolev I, Belinson H, Michaelson DM. Intraneuronal amyloid-beta plays a role in mediating the synergistic pathological effects of apoE4 and environmental stimulation. J Neurochem 2007;103:1031-1040.

38. Villemagne VL, Burnham S, Bourgeat P, et al. Amyloid beta deposition, neurodegeneration, and cognitive decline in sporadic Alzheimer's disease: a prospective cohort study. Lancet Neurol 2013;12:357-367.

39. Hare D, Ayton S, Bush A, Lei P. A delicate balance: iron metabolism and diseases of the brain. Front Aging Neurosci 2013;5:34.

40. de Lima MN, Dias CP, Torres JP, et al. Reversion of age-related recognition memory impairment by iron chelation in rats. Neurobiol Aging 2008;29:1052-1059.

41. Becerril-Ortega J, Bordji K, Freret T, Rush T, Buisson A. Iron overload accelerates neuronal amyloid-beta production and cognitive impairment in transgenic mice model of Alzheimer's disease. Neurobiol Aging 2014;35:2288-2301.

42. Guo $\mathrm{C}$, Wang $\mathrm{T}$, Zheng $\mathrm{W}$, et al. Intranasal deferoxamine reverses iron-induced memory deficits and inhibits amyloidogenic APP processing in a transgenic mouse model of Alzheimer's disease. Neurobiol Aging 2013;34:562-575.

43. Crapper McLachlan DR, Dalton AJ, Kruck TP, et al. Intramuscular desferrioxamine in patients with Alzheimer's disease. Lancet 1991;337:1304-1308.

44. Ayton S, Faux NG, Bush AI. Ferritin levels in the cerebrospinal fluid predict Alzheimer's disease outcomes and are regulated by APOE. Nat Commun 2015;6:6760.

45. Wong BX, Tsatsanis A, Lim LQ, et al. beta-Amyloid precursor protein does not possess ferroxidase activity but does stabilize the cell surface ferrous iron exporter ferroportin. PLoS ONE 2014;9: e114174.

46. McCarthy RC, Park YH, Kosman DJ. sAPP modulates iron efflux from brain microvascular endothelial cells by stabilizing the ferrous iron exporter ferroportin. EMBO Rep 2014;15:809-815.

47. Braak H, Del Tredici K. The pathological process underlying Alzheimer's disease in individuals under thirty. Acta Neuropathol 2011;121:171-181. 